\title{
The Use of Cross-Polarization OCT in Determining the Dynamics of the State of Pathological and Normal Tissues During Radiation and Photodynamic Therapy
}

DOI: $10.17691 /$ stm2015.7.3.17

Received April 9, 2015

T.I. Kalganova, PhD, Junior Researcher, Laboratory of Regenerative Medicine, Institute of Biomedical Technologies';

E.V. Gubarkova, PhD Student, Department of Pathological Physiology ${ }^{1}$; Junior Researcher,

Laboratory for the Study of Optical Structure of Biotissue, Institute of Biomedical Technologiest;

S.V. Gamayunov, MD, PhD, Head of Photodynamic Therapy Department²; Assistant Professor,

Department of Oncology, Postgraduate Faculty ${ }^{1}$; Senior Researcher ${ }^{3}$;

E.B. Kiseleva, PhD, Junior Researcher, Laboratory for the Study of Optical Structure of Biotussie, Institute of Biomedical Technologies';

E.V. Grebenkina, MD, PhD, Gynekologist Oncologist, Photodynamic Therapy Department²;

S.S. Kuznetsov, MD, DSc, Head of Pathological Anatomy Department4; Professor,

Department of Pathological Anatomy'; Leading Researcher;

E.S. Finagina, Intern, Department of Oncology';

N.M. Shakhova, MD, DSc, Leading Researcher, Department of Radiophysical Methods in Medicine;

Leading Researcher, Research Institute of Biomedical Technologies'; Leading Researcher,

Femtosecond Biophotonics Laboratory";

A.V. Maslennikova, MD, DSc, Professor, Department of Oncology';

E.V. Zagaynova, MD, DSc, Director of Institute of Biomedical Technologies';

A. Vitkin, PhD M-CCPM, Senior Scientist, Division of Biophysics and Bioimaging,

Ontario Cancer Institute / Princess Margaret Cancer Centre; Professor, Department of Medical Biophysics ${ }^{6}$;

N.D. Gladkova, MD, DSc, Professor, Vice Director for Science, Institute of Biomedical Technologies ${ }^{1}$

${ }^{1}$ Nizhny Novgorod State Medical Academy, 10/1 Minin and Pozharsky Square, Nizhny Novgorod, 603005,

Russian Federation;

${ }^{2}$ Nizhny Novgorod Regional Oncologic Hospital, 190 Rodionova St., Nizhny Novgorod, 603126,

Russian Federation;

${ }^{3}$ Lobachevsky State University of Nizhni Novgorod, 23 Prospekt Gagarina, Nizhny Novgorod, 603950,

Russian Federation;

${ }^{4}$ N.A. Semashko Nizhny Novgorod Regional Clinical Hospital, 190 Rodionova St., Nizhny Novgorod, 603126,

Russian Federation;

5Institute of Applied Physics, Russian Academy of Sciences, 46 Ulianova St., Nizhny Novgorod, 603950,

Russian Federation;

6University of Toronto, 610 University Avenue, Toronto, Ontario, M5G 2M9, Canada

The aim of the investigation was evaluating the possibilities of cross-polarization optical coherence tomography (CP OCT) to monitor the effectiveness of photodynamic therapy (PDT) and radiation therapy (RT) of the oral cancer and of the cervical cancer.

Materials and Methods. The CP OCT investigation was performed by an OCT-1300U tomograph (Institute of Applied Physics of the Russian Academy of Sciences, LLC "Biomedtech", Russia). The monitoring of the two types of treatment was performed after different periods of exposure: for RT of the oral cancer - once for every 2-3 days throughout the whole course of the treatment, starting from the first day of radiation; for the PDT of the cancers of the skin and cervix uteri — before the exposure, immediately after the exposure, and then at 1 day, 7 day and 1 month after the exposure. Fourteen patients were examined in total.

Results. The results of the study of the medical pathomorphism of different kinds of tumors performed on the 14 patients showed that visual evaluation of CP OCT images of a tumor does not reveal any visible changes in response to RT, however it does register the reaction of the normal mucosa in the area exposed to the radiation. During the PDT of tumors of the skin and cervix mucosa CP OCT was capable of detecting the key morphological changes (edema, necrosis, and structural recovery). It can be applied most effectively at later stages of the follow-up observation (at 30-35 days after PDT) to evaluate the completeness of the recovery of the stromal component of the tissues.

Conclusion. The use of CP OCT contributes to realization of non-invasive monitoring of the responses of tumors and the adjacent normal tissues to PDT and to RT that can be useful for evaluation of the effectiveness of therapy and to help in choosing optimal tactics for the treatment.

Key words: cross-polarization optical coherence tomography; СР ОСТ; cancer of the mouth cavity mucosa; basal-cell skin cancer; squamous cell cancer of the cervix uteri; radiation therapy; photodynamic therapy.

For contacts: Gubarkova Ekaterina Vladimirovna, e-mail: kgybarkova@mail.ru 
A major trend in modern clinical oncology is individualized approach for each patient, i.e. the prescription and correction of the treatment in accordance with the individual biological properties of each tumor and its sensitivity to particular therapeutic exposures. It is known that a complex of consequent changes occurs in the tumor during treatment, called the "tumor response" (or "treatment pathomorphism") [1], with less obvious and earlier changes in the tissue at a molecular-metabolic level preceding the changes in the size and structure of the tumor [2]. The study of the corresponding changes can give valuable information about the sensitivity of the tumor to treatment and can considerably widen the possibilities of therapy individualization. Further development of the methods and the detection of the early responses of the neoplasm to the treatment are priorities of modern oncology.

To achieve this goal, methods of metabolic and functional visualization are widely used to help evaluate the dynamics of the biological activity of the tumor before the occurrence of structural changes. These methods include positron emission tomography (PET) $[3,4]$ and magnetic-resonance tomography (MRT) [5-9]. Currently work has started on the study of the state of the vascular system and metabolism of tumors during radiation therapy (RT) with the use of micro-CT and micro-PET as well as high-frequency ultrasound [10-14].

Biophotonics methods have been widely used to evaluate the dynamics of the metabolic activity of tumors during treatment [15-24].

The method of optical coherence tomography (OCT) based on the analysis of the tissue's back-scattering of low-coherence radiation in the near IR-range allows study of the inner structure of the surface layers of biotissues $[25,26]$ and is used in clinical practice to diagnose a wide spectrum of pathological processes [27]. One of the potential clinical applications of OCT is monitoring the state of malignant neoplasms during and after treatment [27-30]. A study of the state of normal tissues exposed to ionizing radiation during the treatment of malignant neoplasms is equally important in the task of searching for minimal changes in the tumor tissues [28, 29].

This study uses the method of cross-polarization optical coherence tomography (CP OCT) as a tool allowing evaluate the early changes in tumors and the normal adjacent tissues exposed to the anti-tumor treatment [31, 32].

The aim of the investigation was evaluating the possibilities of cross-polarization optical coherence tomography to monitor the effectiveness of photodynamic therapy and radiation therapy of the oral cancer and of the cervical cancer.

\section{Materials and Methods}

Patient's characteristics. CP OCT monitoring of tumor tissue and the normal mucosa of the oral cavity was performed on three patients with histologically confirmed squamous cell oral cancer. The inclusion criteria were the lack of distant metastases and the general state of the patients corresponding to $0-1$ on the ECOG scale [33].

Radiation treatment was performed on a Clinac-600, $6 \mathrm{MeV}$ (Varian Medical Systems, USA) linear accelerator in the standard fractioning mode to a total dose (TD) of 66-70 Gy. The grade of adverse events was identified in accordance with the CTCAE scale [34]. CP OCT images of the cheek mucosae of three healthy volunteers were used as a control.

CP OCT monitoring during PDT was used for 4 patients with histologically confirmed primary basal cell skin cancer and for 7 patients with precancerous diseases (cervical intraepithelial neoplasia, $\mathrm{CIN}$ ) and early (cancer in situ, CIS) cancer of the cervix uteri without any preceding treatment (CIN II-III - in four patients, cancer in situ - in 3 patients, the average age was 32).

PDT was performed according to standard methods [35]. Laser exposure was performed with the use of a semiconductor source of laser radiation, the LakhaMilton, $662 \mathrm{~nm}$ (Milton, Russia). The parameters for exposure were as follows: 1) for the cervix uteri: power density $-0.28 \mathrm{~W} / \mathrm{cm}^{2}$, dose density $-150 \mathrm{~J} / \mathrm{cm}^{2} ; 2$ ) for the skin: power density $-0.30 \mathrm{~W} / \mathrm{cm}^{2}$, dose density for basal cell cancer $-200 \mathrm{~J} / \mathrm{cm}^{2}$.

The study was performed in accordance with the Helsinki declaration (accepted in June 1994 (Helsinki, Finland) and reviewed in October 2000 (Edinburgh, Scotland)) and approved by the Ethical Committee of the Nizhny Novgorod State Medical Academy. Each of the patients provided an informed consent.

Technical characteristics of the CP OCT device. The study was performed on a cross-polarization optical coherence tomograph, the OCT-1300U developed and designed by the Institute of Applied Physics of the Russian Academy of Sciences (Nizhny Novgorod, Russia) with the following technical parameters: probing wavelength $-1.3 \mu \mathrm{m}$, spatial resolution $-15-25 \mu \mathrm{m}$, depth of probing $\sim 1.7 \mathrm{~mm}$; the rate of imaging -1 shot/s. The device is equipped with a flexible endoscopic end probe with a cross scanning range of about $2 \mathrm{~mm}$.

Methods of CP OCT investigation of patients. RT with CP OCT monitoring was performed once every 2-3 days during the whole course of treatment starting from the first day of radiation treatment. The dynamics of the CP OCT images of tumors of the oral cavity and of the normal mucosa of the oral cavity exposed to ionizing radiation were evaluated separately. Reference points were selected in the middle zone of the cheek mucosa as standardizing zones or the scanned normal mucosae, because they are easy to reach for CP OCT investigation and their images are characterized by a distinct layered structure.

The investigation of tumors in oral cavity began from a visual examination, and photographing of the focus of the tumor and identification of the scanning points (using 
the conventional 3, 6, 9, 12 o'clock positions, the center of the tumor and the unchanged mucosa at its border with the tumor). To obtain CP OCT images a sterile end probe was applied directly to the site of interest.

CP OCT monitoring in the case of PDT was performed before the beginning of the treatment, immediately after the procedure was completed, during the early stages of the dynamic observation (on days 1 and 7 after the PDT) and at late stages of the dynamic observation (1 month after PDT). Then a biopsy for morphological analysis was taken from the area of the CP OCT investigation.

Evaluation of the CP OCT images was recorded as a description of the visual characteristics of the CP OCT images in the initial and orthogonal polarizations. The following parameters were evaluated: the intensity of the OCT-signal, its homogeneity, the depth of penetration of the OCT-signal, and the layer structure of the image.

\section{Results}

Investigation of the use of CP OCT to assess the early responses of tumors and adjacent tissues of the mouth cavity to RT. Visually, the squamous cell carcinoma of the mouth cavity mucosa before radiation looks like an exophytic formation with a nodular surface and color ranging from pale to dark pink. The border between the tumor and the adjacent healthy tissues is, as a rule, indistinctly identified (Figure $1(\mathrm{a})$ ).

CP OCT images of the healthy mucosa of the oral cavity (Figure 2) in the initial polarization are characterized by a layered structure where there are three well-visualized contrasting horizontal layers corresponding to the stratified non-keratinized squamous epithelium, the connective stroma (where areas can be seen with lower level signals of different forms having sharp or slightly blurred boundaries), and a submucosal layer with a moderate intensity signal.

On studying the dynamics of the CP OCT images of the normal mucosae of patients during RT of oral cancer it was revealed that changes in the images occurred after the first session of radiation despite an absence of clinical manifestations of the exposure to radiation. In the initial polarization there could be observed a decrease in sharpness of the border between the epithelium and the adjacent connective tissue as well as a decrease in the thickness of the epithelium layer (Figure 3). Throughout the RT the structural properties of the CP OCT images in the initial polarization continued decreasing, and at the maximum extent of reaction to the radiation (after
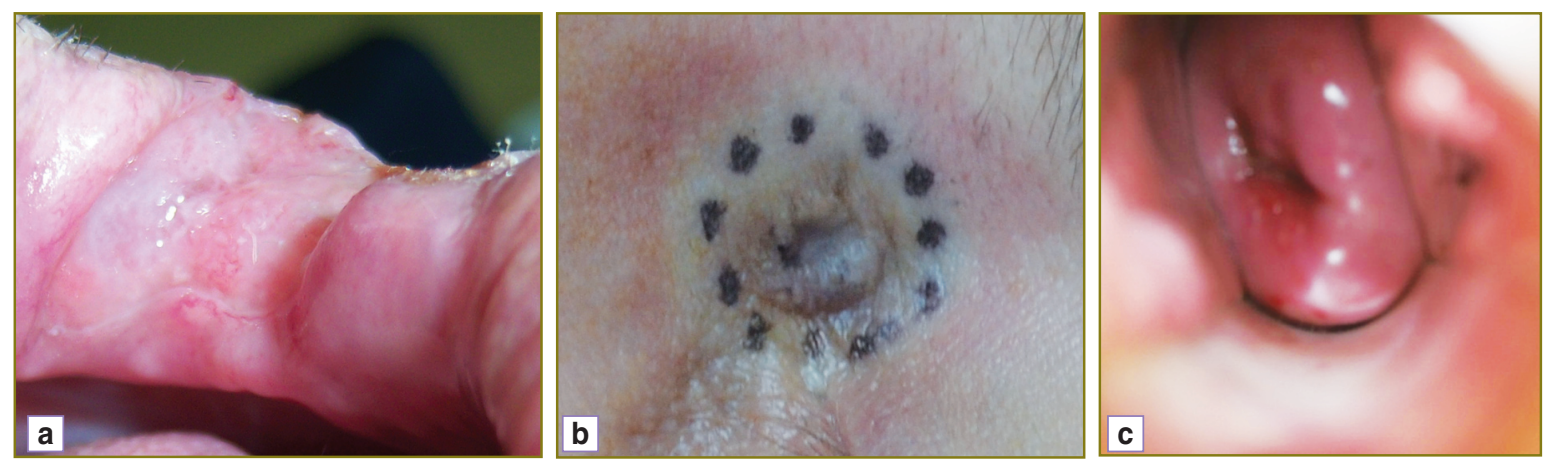

Figure 1. Images of squamous cancer of the mucosa of the mouth cavity (a), basal cell cancer in the skin of the corner of the eye (b) and squamous cell cancer of the cervix uteri (c) before the treatment
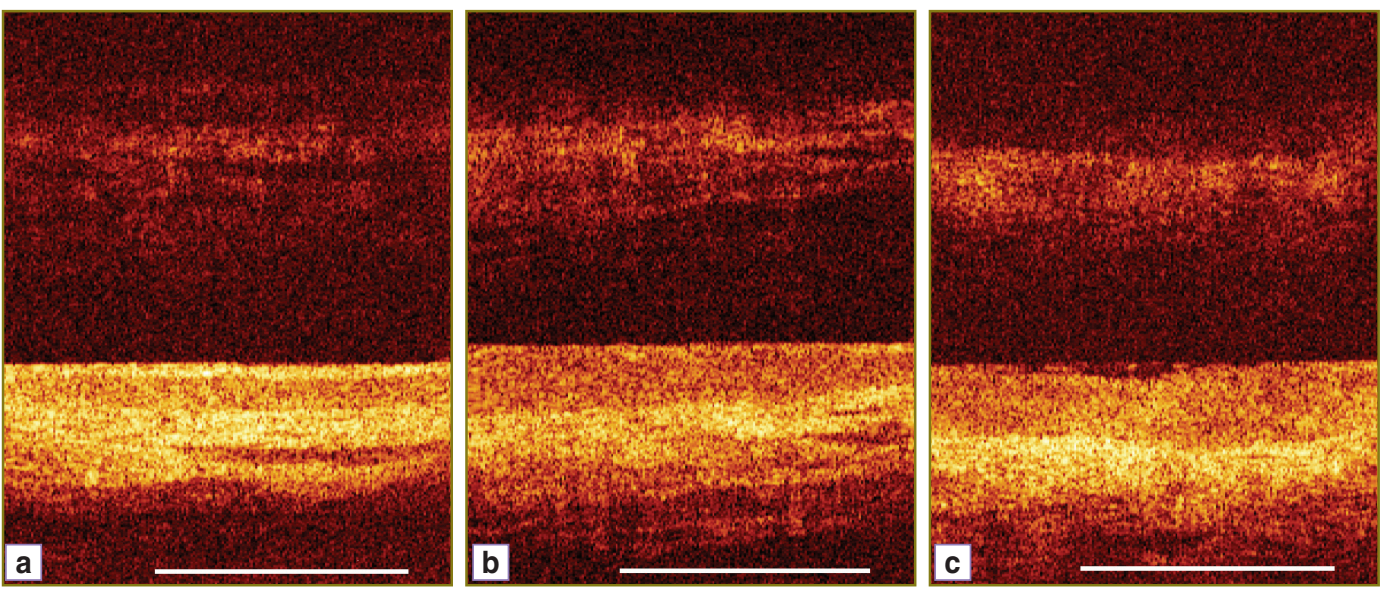

Figure 2. CP OCT images $(\mathrm{a}-\mathrm{c})$ of healthy mucosa of the mouth cavity from three volunteers. Here: CP OCT image in the initial polarization - the lower part of the image and in the orthogonal polarization - the upper part of the image, bar - $1 \mathrm{~mm}$ 

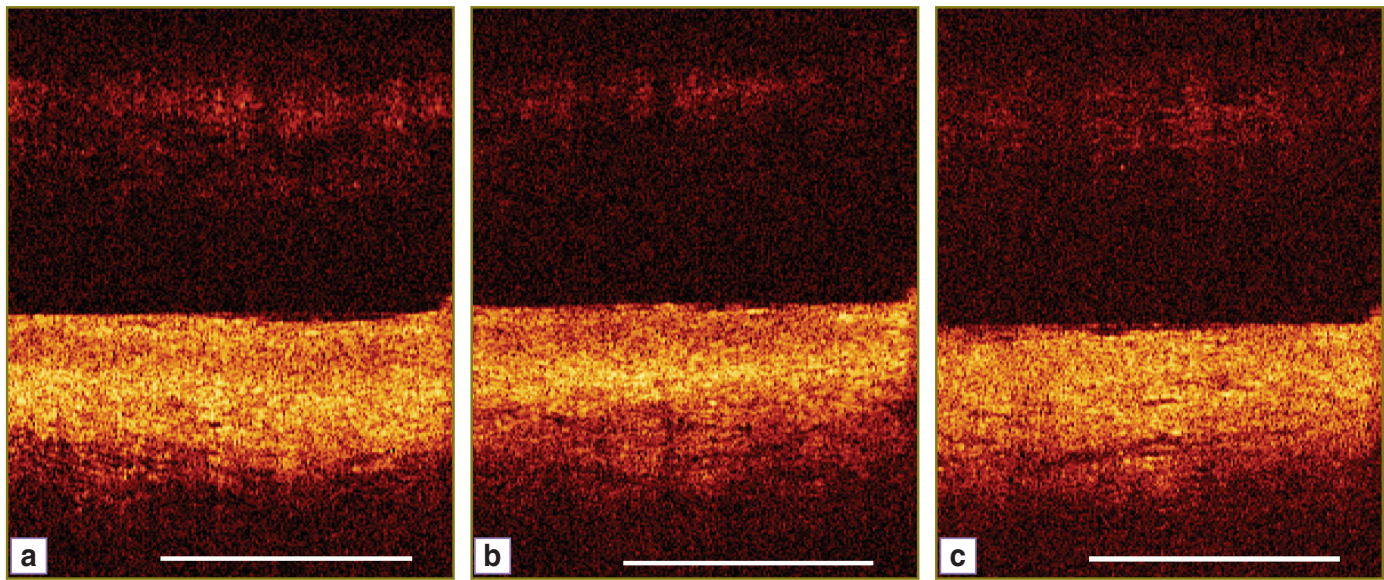

Figure 3. CP OCT images of healthy mucosa of the mouth cavity of the patient with squamous cancer of the mouth cavity after exposure to radiation; the dose was $3 \mathrm{~Gy}(\mathrm{a}), 16 \mathrm{~Gy}(\mathrm{~b}), 34 \mathrm{~Gy}(\mathrm{c})$. Here: CP OCT image in the initial polarization - the lower part of the image and in the orthogonal polarization — the upper part of the image, bar $-1 \mathrm{~mm}$
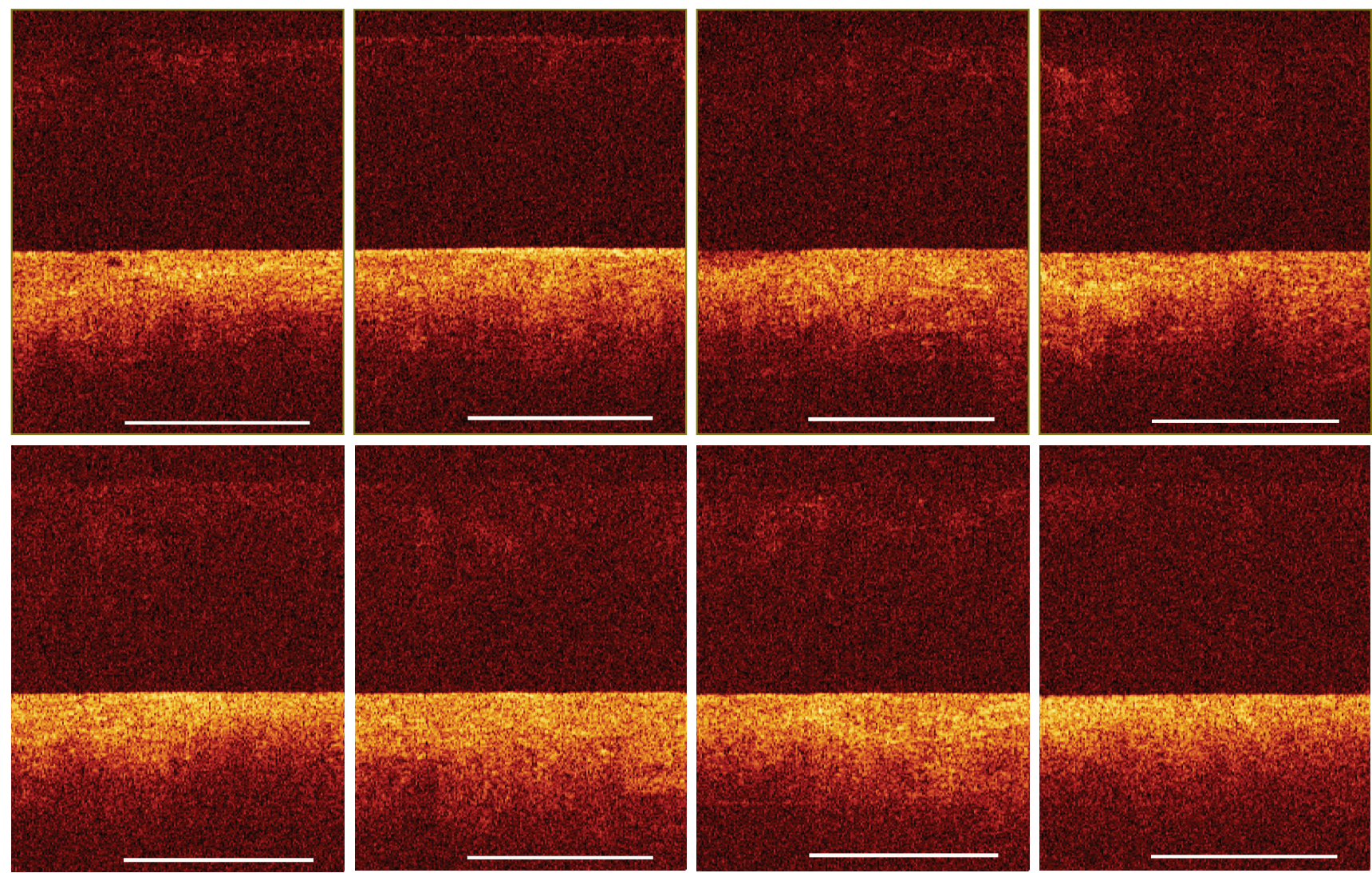

b

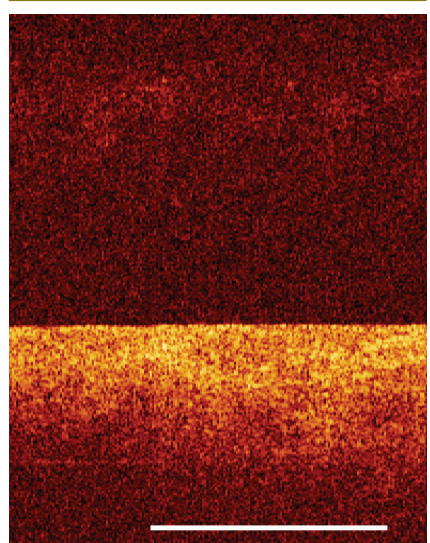

C

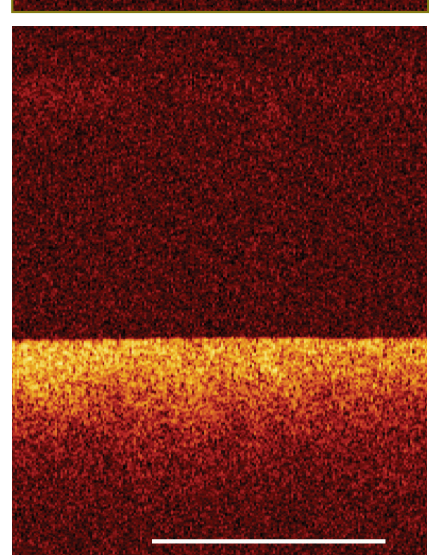

d

Figure 4. CP OCT images of squamous cancer of the mucosa of the mouth cavity of the patient in different zones $-3 \mathrm{~h}(\mathrm{a}), 6 \mathrm{~h}(\mathrm{~b})$, $9 \mathrm{~h}$ (c), center (d). Here: CP OCT image in the initial polarization - the lower part of the image and in the orthogonal polarization the upper part of the image, bar $-1 \mathrm{~mm}$; the upper row - before radiation therapy, the lower row — radiation 34 Gy

TD of 24-26 Gy) the images were characterized by the complete loss of structural properties in the initial polarization and a considerable decrease in the intensity of the signal in the orthogonal polarization.

In the initial polarization, the tumor tissue was characterized by an absence of structure in the CP OCT images, preventing visualization of the corresponding layers (Figure 4). In orthogonal polarization the signal in the images is almost absent. The visual evaluation of CP OCT images of tumor tissue in the image dynamics did not allow the identification of changes even when using more than half of the planned dose. 

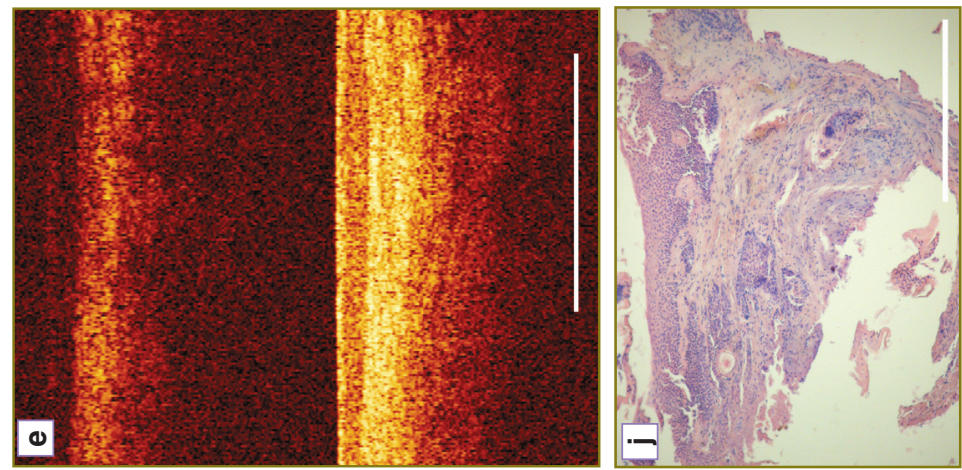

Ф)

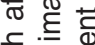

ป

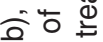

늘

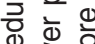

으으을 홍

을.

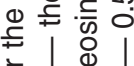

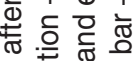

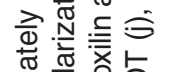
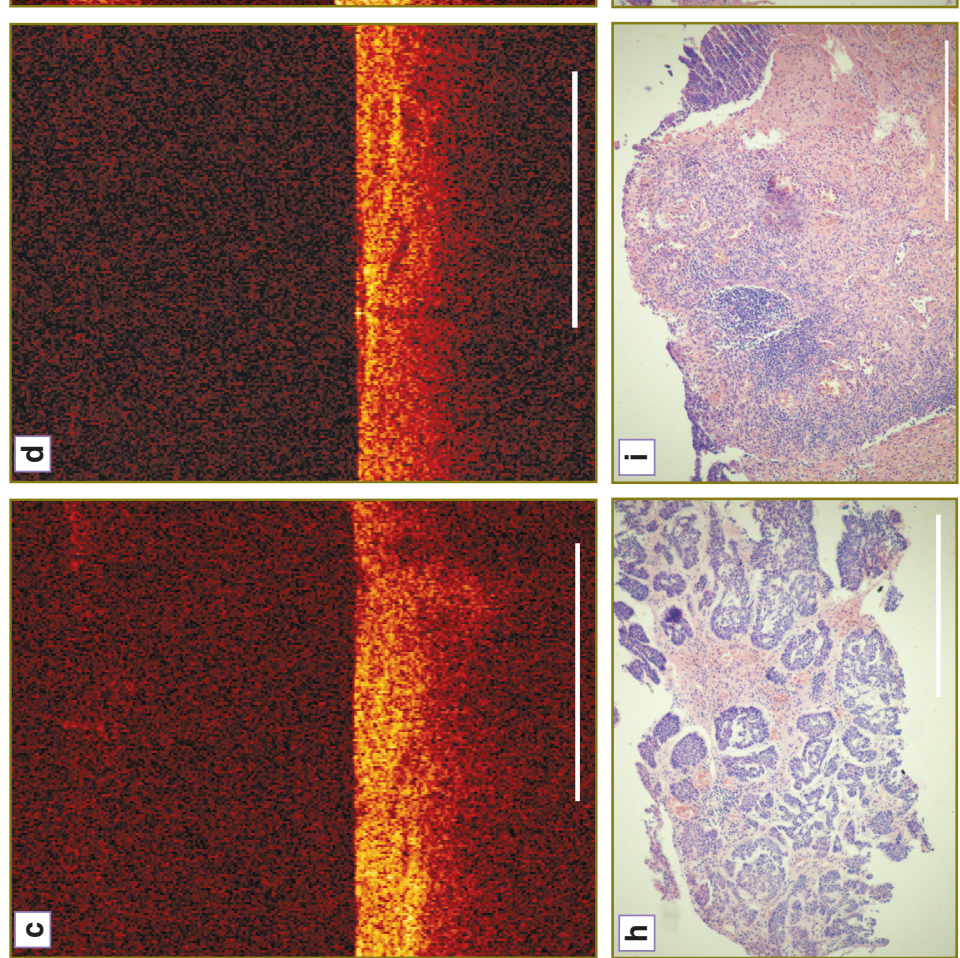

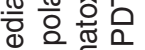

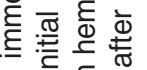

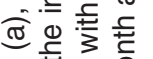

등 응 으

变

$\stackrel{\Phi}{=}$ क ।

능 응 은

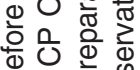

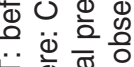

占这 응 을

이응

는 粞

웜음 웅

के 产

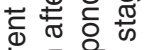

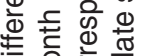

๘

क

윰ำ

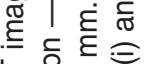

它 윻ㄴ
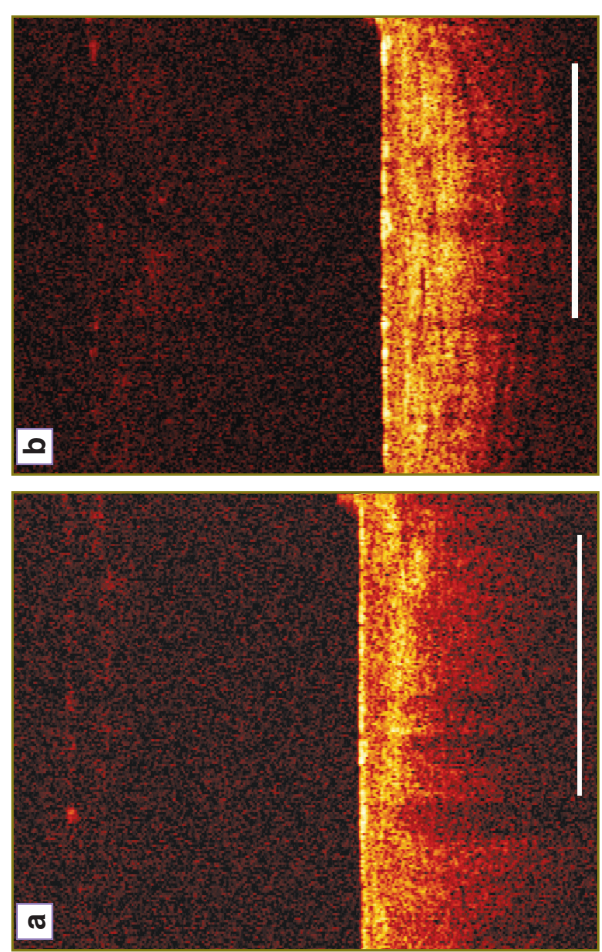

O

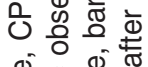

ब.

ब ह

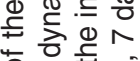

पั

离步占

O 원은

Ф 㔛

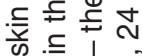

ब 응

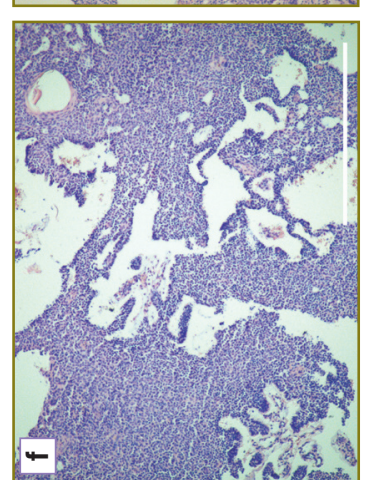

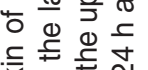

Investigation of the potential for using CP OCT for evaluation of the early response of tumors and of normal skin to PDT. Visually, before the beginning of the therapy, the basal cell skin cancer looks like an exophytic formation, often with iliac erosion and edges outlined with a light brown or pink color. The border between the tumor and the adjacent healthy tissues was, as a rule, well defined (Figure 1 (b)).

Before PDT typical CP OCT images were obtained of the skin tumor (Figure 5 (a)). In the initial polarization a damaged, layered structure could be visualized which corresponded to the presence of the groups of basaloid cells on the histological preparation (Figure 5 (f)). In the orthogonal polarization the signal was absent showing a lack of, or immaturity of, depolarizing connective tissue structures (collagen fibers) (See Figure 5 (f)). Immediately after the completion of the laser exposure (Figure 5 (b)) in the initial polarization of the CP OCT image there was an increase in the depth of signal penetration, and regions of alternating strong and weaker signals with irregular contours and indistinct borders could be visualized, indicating the presence of the edema seen on the histological preparation (Figure 5 (g)); in the orthogonal polarization the signal was absent from the image.

The CP OCT image in the initial polarization after 24 hours (Figure 5 (c)) indicates that the layered structure is damaged and that there are signs of edema as confirmed by the histological preparation (Figure 5 (h)); in the orthogonal polarization the signal is still absent.

At 7 days there is morphological correspondence to necrosis (Figure 5 (i)) in the CP OCT image (Figure 5 (d)) in that the initial polarization indicates an absence of structures, while the image shows a moderate or high level of signal especially at the surface of the image. There is a uniform and rapid attenuation of the signal with depth. The signal is absent from the orthogonal polarization. 
After 1 month the CP OCT image (Figure 5 (e)) in the intensity of the signal in the initial polarization shows that the layered structure of the tissue has been restored, while in the orthogonal polarization there is also an intense signal indicating the appearance and maturing of depolarized structures (collagen fibers) and this corresponds to the formation of the connective tissue scar seen on the histological preparation (Figure 5 (j)).

Investigation of the potential for using CP OCT for evaluation of the early response of tumors and the adjacent tissues of the cervix uteri treated with PDT. The most frequent visual characteristics of squamous cancer of the cervix uteri are its deformations and local hyperemia of the exocervix, whereas colposcopic manifestations of earlier forms of neoplasia are thought of as atypical colposcopic signs (Figure 1 (c)).

For the CP OCT images of the tumor area before PDT (Figure 6 (a)) there is an intense signal without layer visualization in the initial polarization and the lack of any signal in the orthogonal polarization. The low contrast area, most probably, corresponds to the gland with an open duct. On the histological preparation the squamous cancer of the cervix uteri is characterized by the presence of atypical, polymorphous cells of multilayer squamous epithelium forming groups and fields divided by narrow layers of fibrous tissues. A small number of small blood vessels are visible (Figure $6(e)$ ). The appearance of a layered structure in the tumor zone immediately after PDT was a new discovery (Figure 6 (b)); it can be explained by the contrasting effect typical of this period of observation of the tissue edema (Figure 6 (f)). Furthermore, small blood-filled vessels were visible at places on the histological preparations.

At 7 days, when morphologically total tumor necrosis can be registered (Figure $6(\mathrm{~g})$ ), the CP OCT image shows a typical increase of the signal intensity in the initial polarization and a complete loss of signal in the orthogonal polarization (Figure 6 (c)).

At 1 month after PDT the complete recovery of the structure of the cervix uteri can be visualized, however the epithelium is immature (Figure $6(\mathrm{~h})$ ) which causes the absence of a distinct layered structure in the $\mathrm{CP}$ OCT image (Figure 6 (d)). A fairly intense signal in the orthogonal polarization testifies to the restoration of the collagen with its capacity for depolarization.

Discussion. These results allow us to draw preliminary conclusions about the applicability of CP OCT for the lifetime monitoring of different kinds of treatment of external tumors. At the same time, this limited series of investigations raised a number of new issues that require further studies.

Thus, we found that CP OCT is informative only with regard to the non-tumor tissues, whereas during the monitoring of PDT this method is capable of visualizing the changes in the tumor focus as well as in the perifocal zone. The CP OCT images obtained of the unchanged skin at the border with the tumor both before treatment and after exposure to PDT, demonstrate the presence
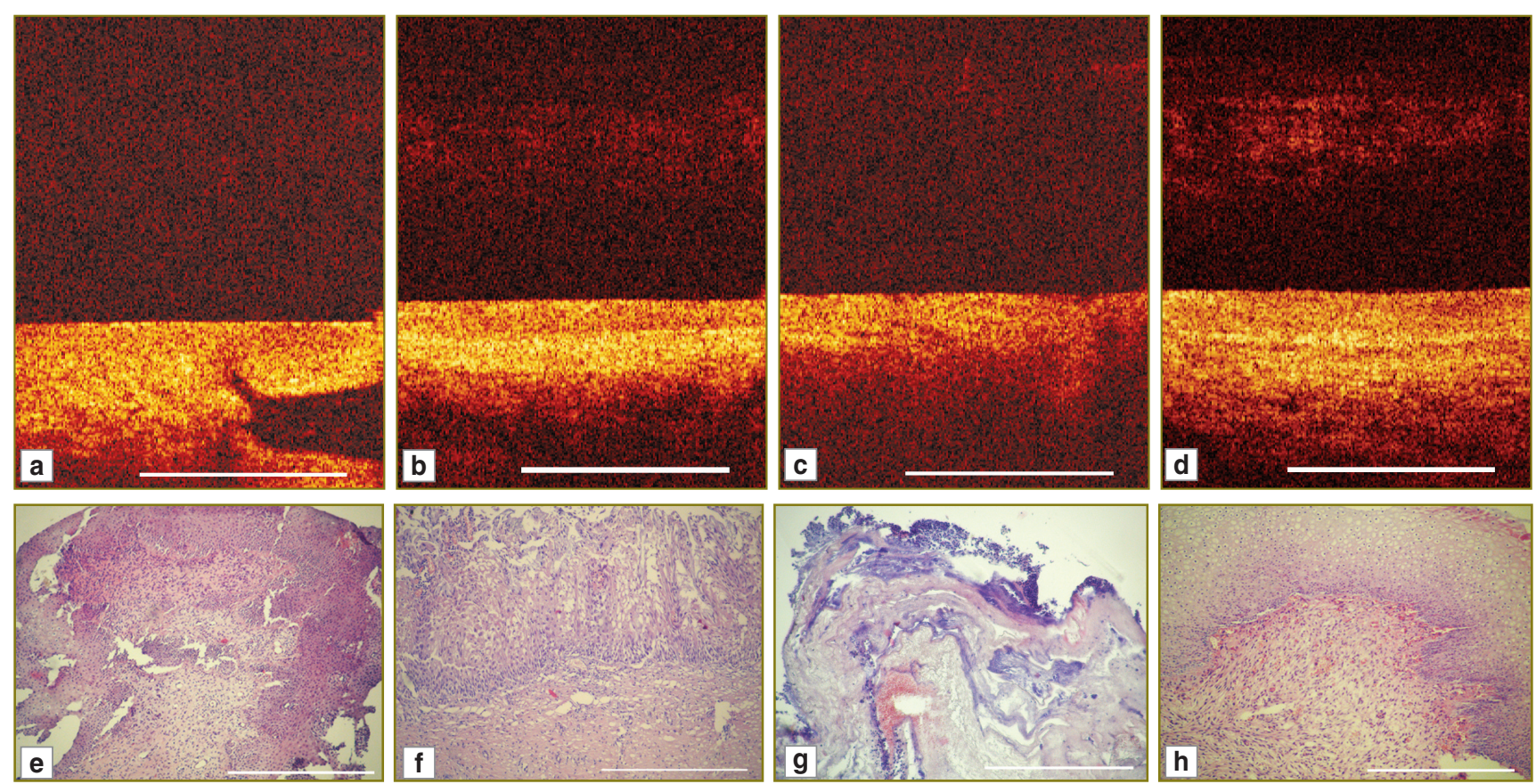

Figure 6. Squamous cancer of the cervix uteri - the zone of transformation, at the 6 o'clock position of the conditional clock face, CIS. CP OCT images: before the treatment (a), immediately after PDT (b), 7 days after PDT (c) and 1 month after PDT (d). Here: CP OCT image in the initial polarization — the lower part of the image and in the orthogonal polarization — the upper part of the image, bar $-1 \mathrm{~mm}$. The corresponding histological preparations stained with hematoxilin and eosin: before the treatment (e), immediately after PDT (f), 7 days after PDT $(\mathrm{g})$ and 1 month after PDT $(\mathrm{h})$, bar $-0.5 \mathrm{~mm}$ 
of a layered structure in the initial polarization and in the signal in orthogonal polarization. These results reflect the properties of healthy tissue and the preservation of these signs on day 7 following PDT, which demonstrates the preservation of the collateral zone. On PDT monitoring of neoplasia of the cervix uteri we observed that in the CP OCT images of the unchanged mucosa of the cervix uteri exposed to PDT, as with the images of the skin before treatment, there was a layered structure typical of healthy tissue, as evidenced in the direct polarization and by the presence of a signal in the orthogonal polarization. However, unlike the skin, these signs were not preserved on day 7 after PDT, indicating probable damage to the collateral zone.

The absence of obvious changes in the CP OCT images of tumors of the oral cavity mucosa during RT could be the result of a number of factors. Firstly, viable tumor tissue and tumor tissue in a dystrophic state and undergoing necrosis can have common visual OCT signals that do not allow differentiation of the processes of neoplasm regression that have just started. Secondly, at the early stage before RT starts there is no wellordered structure of the connective tissue matrix at the location of the tumor, so this could be the reason for the significant lack of the signal in the orthogonal CP OCT images. We believe that continuation of the monitoring at later stages will enable us to register the typical changes in CP OCT images in the tumor zone. To obtain more information and objectivity in the data it is essential to perform extra processing of the results, including calculation of the numeric parameters of the CP OCT images.

With regard to the different dynamics of the optical characteristics of the skin border zones and the mucosa of the cervix uteri after PDT it is reasonable to presume that there are differences between these organs in respect of the accumulation of the photosensitizer, which leads to the demonstrable damage to the collateral zone during PDT of the tumor of the cervix uteri. However the CP OCT-control images of the later results (1 month after PDT) testify to the restoration of the properties of healthy tissues in the tumor zone as well in adjacent areas in both locations. To prove that this is the case it would be necessary to continue the studies with the use of combined monitoring - a combination of both CP OCT and fluorescent visualization. However, at this stage it is undoubtedly reasonable to use CP OCT monitoring of the adjacent normal tissues for the purpose of predicting the actual zone of damage, evaluating the quality of the scar and the functional and cosmetic results of the treatment. Analysis of the polarization OCT component could evidently be useful for early diagnosis of any exacerbation of the tumor in the scar and for the selection of the optimal zones for biopsy for morphological control.

Conclusion. The use of CP OCT in clinical conditions for the investigation of medical pathomorphosis in tumors and the evaluation of the response of the normal adjacent tissues to radiation therapy and photodynamic therapy has great potential. With further development the method could become a non-invasive alternative to the morphological investigation of a series of biopsies to control the immediate and subsequent results of the treatment. It is also of interest to use such non-invasive CP OCT investigation at the stage of planning the therapy as well as during treatment in order to evaluate the effectiveness of the primary reactions and therefore to individualize the modes of exposure. To implement all these approaches, our studies will continue.

Study Funding. The studies were funded by the program of the Government of the Russian Federation, contract No14.B25.31.0015.

Conflicts of Interest. The authors do not have any conflict of interests.

\section{References}

1. Grabovoy A.N., Tarasova T.O., Koshubarova M.V. Histological evaluation of tumor response to chemo-/ radiotherapy. Klinicheskaya onkologiya 2012; 6(2): 138-143.

2. Tannock I.F., Lee C. Evidence against apoptosis as a major mechanism for reproductive cell death following treatment of cell lines with anti-cancer drugs. $\mathrm{Br} J$ Cancer 2001; 84(1): 100-105, http://dx.doi.org/10.1054/bjoc.2000.1538.

3. Postema E.J., McEwan A.J.B., Riauka T.A., Kumar P., Richmond D.A., Abrams D.N., Wiebe L.I. Initial results of hypoxia imaging using 1- $\alpha-\mathrm{D}-\left(5-\right.$ deoxy-5- $\left[{ }^{18} \mathrm{~F}\right]$-fluoroarabinofuranosyl)-2nitroimidazole $\left({ }^{18} \mathrm{~F}-\mathrm{FAZA}\right)$. Eur J Nucl Med Mol Imaging 2009; 36(10): 1565-1573, http://dx.doi.org/10.1007/s00259-0091154-5.

4. Grosu A.L., Souvatzoglou M., Röper B., Dobritz M., Wiedenmann N., Jacob V., Wester H.J., Reischl G., Machulla H.J., Schwaiger M., Molls M., Piert M. Hypoxia imaging with FAZA-PET and theoretical considerations with regard to dose painting for individualization of radiotherapy in patients with head and neck cancer. Int J Radiat Oncol Biol Phys 2007; 69(2): 541-551, http://dx.doi.org/10.1016/j.jirobp.2007.05.079.

5. Gilad A.A., Israely T., Dafni H., Meir G., Cohen B., Neeman M. Functional and molecular mapping of uncoupling between vascular permeability and loss of vascular maturation in ovarian carcinoma xenografts: the role of stroma cells in tumor angiogenesis. Int J Cancer 2005; 117(2): 202-211, http://dx.doi. org/10.1002/ijc.21179.

6. Kiessling F., Huppert J., Zhang C., Jayapaul J., Zwick S., Woenne E.C., Mueller M.M., Zentgraf H., Eisenhut M., Addadi Y., Neeman M., Semmler W. RGD-labeled USPIO inhibits adhesion and endocytotic activity of alpha $v$ beta3-integrin-expressing glioma cells and only accumulates in the vascular tumor compartment. Radiology 2009; 253(2): 462-469, http://dx.doi. org/10.1148/radiol.2532081815.

7. Frascione D., Diwoky C., Almer G., Opriessnig P., Vonach C., Gradauer K., Leitinger G., Mangge H., Stollberger R., Prassl R. Ultrasmall superparamagnetic iron oxide (USPIO)based liposomes as magnetic resonance imaging probes. Int J Nanomedicine 2012; 7: 2349-2359, http://dx.doi.org/10.2147/ IJN.S30617.

8. Tripathy D., Jiang L., Rao N., McColl R., Xie X., Weatherall P., Story M., Ding L., Mason R. Blood oxygen 
level dependent (BOLD) contrast MRI and breast cancer chemotherapy response. J Clin Oncol (Meeting Abstracts) 2006; 24(18 Suppl): 10514.

9. Warren R., Hayes C., Pointon L., Hoff R., Gilbert F.J., Padhani A.R., Rubin C., Kaplan G., Raza K., Wilkinson L., Hall-Craggs M., Kessar P., Rankin S., Dixon A.K., Walsh J., Turnbull L., Britton P., Sinnatamby R., Easton D., Thompson D., Lakhani S.R., Leach M.O.; UK MRC study of MRI screening for breast cancer in women at high risk (MARIBS). A test of performance of breast MRI interpretation in a multicentre screening study. Magn Reson Imaging 2006; 24(7): 917-929, http://dx.doi.org/10.1016/j.mri.2006.03.004.

10. Pantaleo M.A., Nannini M., Maleddu A., Fanti S., Nanni C., Boschi S., Lodi F., Nicoletti G., Landuzzi L., Lollini P.L., Biasco G. Experimental results and related clinical implications of PET detection of epidermal growth factor receptor (EGFr) in cancer. Ann Oncol 2009; 20(2): 213-226, http://dx.doi. org/10.1093/annonc/mdn625.

11. Weber B., Winterdahl M., Memon A., Sorensen B.S., Keiding S., Sorensen L., Nexo E., Meldgaard P. Erlotinib accumulation in brain metastases from non-small cell lung cancer: visualization by positron emission tomography in a patient harboring a mutation in the epidermal growth factor receptor. J Thorac Oncol 2011; 6(7): 1287-1289, http://dx.doi. org/10.1097/JTO.0b013e318219ab87.

12. Gupta S., Siddiqui S., Haldar P., Raj J.V., Entwisle J.J., Wardlaw A.J., Bradding P., Pavord I.D., Green R.H., Brightling C.E. Qualitative analysis of high-resolution CT scans in severe asthma. Chest 2009; 136(6): 1521-1528, http://dx.doi. org/10.1378/chest.09-0174.

13. Bussink J., Kaanders J.H., van der Graaf W.T., Oyen W.J. PET-CT for radiotherapy treatment planning and response monitoring in solid tumors. Nat Rev Clin Oncol 2011; 8(4): 233-242, http://dx.doi.org/10.1038/nrclinonc.2010.218.

14. Kolios M.C., Czarnota G.J., Lee M., Hunt J.W., Sherar M.D. Ultrasonic spectral parameter characterization of apoptosis. Ultrasound Med Biol 2002; 28(5): 589-597, http:// dx.doi.org/10.1016/S0301-5629(02)00492-1.

15. Tromberg B.J., Pogue B.W., Paulsen K.D., Yodh A.G., Boas D.A., Cerussi A.E. Assessing the future of diffuse optical imaging technologies for breast cancer management. Med Phys 2008; 35(6): 2443-2451, http://dx.doi.org/10.1118/1. 2919078.

16. Maslennikova A., Orlova A., Golubjatnikov G., Kamensky V., Plekhanov V., Shakhova N., Snopova L., Babaev A., Prjanikova T. Noninvasive detection of tumour's oxygen status using diffuse optical tomography. EJC Supplements 2009; 7(2): 160, http://dx.doi.org/10.1016/S13596349(09)70545-2.

17. Zhu Q., DeFusco P.A., Ricci A. Jr., Cronin E.B., Hegde P.U., Kane M., Tavakoli B., Xu Y., Hart J., Tannenbaum S.H. Breast cancer: assessing response to neoadjuvant chemotherapy by using US-guided near-infrared tomography. Radiology 2013; 266(2): 433-442, http://dx.doi. org/10.1148/radiol.12112415.

18. Cerussi A.E., Tanamai V.W., Hsiang D., Butler J., Mehta R.S., Tromberg B.J. Diffuse optical spectroscopic imaging correlates with final pathological response in breast cancer neoadjuvant chemotherapy. Philos Trans A Math Phys Eng Sci 2011; 369(1955): 4512-4530, http://dx.doi.org/10.1098/ rsta.2011.0279.

19. Chung S.H., Yu H., Su M.-Y., Cerussi A. E., Tromberg B.J. Molecular imaging of water binding state and diffusion in breast cancer using diffuse optical spectroscopy and diffusion weighted MRI. J Biomed Opt 2012; 17(7): 071304, http://dx.doi. org/10.1117/1.JBO.17.7.071304.

20. O'Sullivan T., Leproux A., Chen J., Bahri S., Matlock A., Roblyer Darren, McLaren C.E., Chen W., Cerussi A., Su M., Tromberg B.J. Optical imaging correlates with magnetic resonance imaging breast density and reveals composition changes during neoadjuvant chemotherapy. Breast Cancer Rese 2013; 15(1): R14, http://dx.doi.org/10.1186/bcr3389.

21. Ueda S., Saeki T. Near-infrared optical imaging of cancer vascular remodeling after antiangiogenic therapy. Breast Cancer 2014; 21(6): 776-769, http://dx.doi.org/10.1007/s12282-0140534-2.

22. Xiang L., Xing D., Gu H., Yang D., Yang S., Zeng L., Chen W.R. Real-time optoacoustic monitoring of vascular damage during photodynamic therapy treatment of tumor. J Biomed Opt 2007; 12(1): 014001, http://dx.doi. org/10.1117/1.2437752.

23. Chen B., Crane C., He C., Gondek D., Agharkar P., Savellano M.D., Hoopes P.J., Pogue B.W. Disparity between prostate tumor interior versus peripheral vasculature in response to verteporfin-mediated vascular-targeting therapy. Int J Cancer 2008; 123(3): 695-701, http://dx.doi.org/10.1002/ ijc.23538.

24. Ueda S., Roblyer D., Cerussi A., Durkin A., Leproux A., Santoro Y., Xu S., O'Sullivan T.D., Hsiang D., Mehta R., Butler J., Tromberg B.J. Baseline tumor oxygen saturation correlates with a pathologic complete response in breast cancer patients undergoing neoadjuvant chemotherapy. Cancer Res 2012; 72(17): 4318-4328, http://dx.doi.org/10.1158/0008-5472. CAN-12-0056.

25. Huang D., Swanson E.A., Lin C.P., Schuman J.S., Stinson W.G., Chang W., Hee M.R., Flotte T., Gregory K., Puliafito C.A., et al. Optical coherence tomography. Science 1991; 254(5035): 1178-1181, http://dx.doi.org/10.1126/ science.1957169.

26. Fercher A.F., Drexler W., Hitzenberger C.K., Lasser T. Optical coherence tomography - principles and applications. Rep Prog Phys 2003; 66(22): 239-303, http://dx.doi. org/10.1088/0034-4885/66/2/204.

27. Fomina Yu.V., Gladkova N.D., Maslennikova A.V., Urutina M.N., Radenska-Lopovok S.G., Ostrovskiy A.D., Rabinovich I.M., Feldshtein F.I. Opticheskaya kogerentnaya tomografiya v stomatologii. V kn.: Rukovodstvo po opticheskoy kogerentnoy tomografii [Optic coherence tomography in dentistry. In: Optic coherence tomography guide]. Pod red. Gladkovoy N.D., Shakhovoy N.M., Sergeeva A.M. [Gladkova N.D., Shakhova N.M., Sergeev A.M. (editors)]. Moscow: Fizmatlit, Meditsinskaya kniga; 2007; p. 203-246.

28. Maslennikova A.V., Balalayeva I.V., Gladkova N.D., Karaboot M.M., Kiseleva Ye.B., Ixanov R.R., Ilyin N.I., Sokurenko V.N. Use of optical coherence tomography for prognosis of stage of mucositis development. Voprosy onkologii 2009; 55(5): 572-579.

29. Davoudi B., Lindenmaier A., Standish B.A., Allo G., Bizheva K., Vitkin A. Noninvasive in vivo structural and vascular imaging of human oral tissues with spectral domain optical coherence tomography. Biomed Opt Express 2012; 3(5): 826839, http://dx.doi.org/10.1364/BOE.3.000826.

30. Standish B.A., Lee K.K., Jin X., Mariampillai A., Munce N.R., Wood M.F., Wilson B.C., Vitkin I.A., Yang V.X. Interstitial Doppler optical coherence tomography as a local tumor necrosis predictor in photodynamic therapy of prostatic 
carcinoma: an in vivo study. Cancer Res 2008; 68(23): 99879995, http://dx.doi.org/10.1158/0008-5472.CAN-08-1128.

31. Gelikonov V.M., Gelikonov G.V. New approach to crosspolarized optical coherence tomography based on orthogonal arbitrarily polarized modes. Laser Physics Letters 2006; 3(9): 445-451, http://dx.doi.org/10.1002/lapl.200610030.

32. Feldchtein F.I., Gelikonov V.M., Gelikonov G.V. Polarization-sensitive common path optical coherence reflectometry/tomography device. Patent US 7,728,985 B2. 2010.
33. The Eastern Cooperative Oncology Group. URL: http:// ecog-acrin.org/resources/ecog-performance-status.

34. Cancer Therapy Evaluation Program. Common terminology criteria for adverse events. Version 4.0. 2009. URL: http://www.nih.gov/.

35. Tsyb A.F., Kaplan M.A., Romanenko Yu.S., et al. Klinicheskie aspekty fotodinamicheskoy terapii [Clinical aspects of photodynamic therapy]. Kaluga: Izdatel'stvo nauchnoy literatury N.F. Bochkarevoy; 2009. 